\title{
What are the impacts of nature conservation interventions on human well-being: a systematic map protocol
}

Madeleine Bottrill ${ }^{*}$, Samantha Cheng ${ }^{2}$, Ruth Garside ${ }^{3}$, Supin Wongbusarakum ${ }^{4}$, Dilys Roe ${ }^{5}$, Margaret B Holland ${ }^{6}$, Janet Edmond ${ }^{1}$ and Will R Turner ${ }^{1}$

\begin{abstract}
Background: International policy has sought to emphasize and strengthen the link between the conservation of natural ecosystems and human development. Furthermore, international conservation organizations have broadened their objectives beyond nature-based goals to recognize the contribution of conservation interventions in sustaining ecosystem services upon which human populations are dependent. While many indices have been developed to measure various human well-being domains, the strength of evidence to support the effects, both positive and negative, of conservation interventions on human well-being, is still unclear.

Methods/Design: This protocol describes the methodology for examining the research question: What are the impacts of nature conservation interventions on different domains of human well-being in developing countries? Using systematic mapping, this study will scope and identify studies that measure the impacts of nature conservation interventions on human well-being at local to regional scales. The primary objective of this study is to synthesize the state and distribution of the existing evidence base linking conservation and human well-being. In addition, a theory of change approach will be used to identify and characterize the causal linkages between conservation and human well-being, with attention on those studies that examine the role of ecosystem services. Key trends among the resulting studies will be synthesized and the range of studies organized and presented in a graphical matrix illustrating the relationships between types of interventions and types of outcomes. Results of the study are intended to help conservation and development practitioners and the academic community to improve research studies and conservation practices in developing countries in order to achieve both conservation and human well-being outcomes.
\end{abstract}

Keywords: Conservation, Ecosystem services, Human Well-being, Poverty

\section{Background}

The World Conservation Strategy, published by the International Union for Conservation of Nature (IUCN), the United Nations Environment Programme (UNEP) and World Wildlife Fund (WWF) in 1980 [1] was the first key international policy program to strengthen the links between nature conservation and human development [2]. Throughout the 1980s and 1990s, conservation and development organizations promoted and implemented a large number of initiatives aimed at enhancing the benefits of nature conservation for populations at both local and

\footnotetext{
* Correspondence: mbottrill@conservation.org

'Conservation International, 2011 Crystal Drive, Suite 500, Arlington, VA 22202, USA

Full list of author information is available at the end of the article
}

wider scales. These have taken the form of integrated conservation and development projects, community-based natural resource management, community conservation and so on. The 1980s also witnessed an increased focus on human rights within the conservation movement, particularly on indigenous rights and community displacement from protected areas. As early as 1975, the IUCN General Assembly adopted a Recommendation that indigenous peoples' rights should be taken into account in national parks and other protected areas and this was reaffirmed at the 1982 World Parks Congress and at subsequent IUCN meetings [3].

This attention to the human dimensions of conservation has increased significantly since the turn of the new millennium. A wide range of reports such as the Millennium 
Ecosystem Assessment [4] and The Economics of Ecosystems and Biodiversity [5] have attempted to synthesize knowledge of the links between nature and human well-being, while international policy initiatives such as the Convention on Biological Diversity [6], the UN Conference on Sustainable Development Rio + 20 [7], the Millennium Development Goals and their successors [8] have emphasized how sustaining natural ecosystems is linked to benefits for human well-being. These links include essential ecosystem services such as water purification, fisheries, and pollination that underpin human health, contribute to food security, and support livelihoods.

In parallel to policy shifts, increasingly, several major international conservation organizations, including Birdlife International, Conservation International, The Nature Conservancy and Fauna \& Flora International explicitly reference people in their mission and vision statements and aspire to achieve socially beneficial outcomes from their conservation efforts $[9,10]$. Conservation International (CI) specifically revised its mission in 2007 in order to support human well-being by restoring and protecting ecosystems that provide essential goods and services. Recently, guidance to address social results and human well-being targets and outcomes in conservation projects has been developed (e.g., [11-13]).

This evolution towards a greater emphasis on the human dimensions of conservation efforts has occurred for a number of reasons. Over the years, conservation has been portrayed as both a win-win solution for poverty alleviation and sustainable development, and as a constraint on economic growth [14]. While several conservation projects have achieved both conservation and development goals [15-17], conflicts and negative relationships between conservation and human wellbeing have also been highlighted [18], including loss of access rights [19], human-wildlife conflict [20], and most controversially - evictions from protected areas [21]. Thus, conservation policy has been dually influenced by a need to demonstrate contributions to broader development goals (e.g., USAID's Biodiversity Policy 2014, [22]) as well as a genuine desire to secure and ensure the longevity of natural ecosystems upon which vulnerable populations depend [23].

Underlying this increasing focus on the human dimensions of conservation, several predominant hypotheses exist about the explicit effects of conservation interventions on both the tangible (e.g. economic and material wealth, physical and psychological health) to the intangible (e.g., social cohesion, culture, equity and good governance) domains of human well-being (Figure 1). These domains of human well-being are often interdependent and mutually reinforcing. For example, the presence of tangible wellbeing benefits such as secure jobs and good individual physical health can influence household and community well-being, while good governance can result in security and access to livelihood resources that in turn enhance economic wellbeing $[24,25]$.

While many indices have been developed to document or measure various human well-being domains of conservation interventions $[9,23,26]$, these have not been associated with approaches or tools for critically assessing the strength of these relationships, nor the consequences of these outputs on management decisions. With an increasing focus on human dimensions of conservation, decisions are necessary about what interventions are effective at meeting social and biophysical objectives, which indicators are the right ones to measure progress, how and when changes are expected to occur, and what evidence is available to support these decisions. Yet the state of current evidence or information from relevant and rigorous research, documenting the impacts of nature conservation on human well-being is unclear. For example, while it is widely recognized both in literature and emergent policy that ecosystem services are a vital component of environmental provision for human well-being (Figure 1), many questions still remain around the specific role they play and the causal relationships between services and outcomes [27]. As illustrated for direct payment schemes, for example (Figure 2), conservation interventions might affect human well-being through direct provision of income from payments that then facilitate better livelihoods, but also in directing through ecosystem services. For example, payments might promote advocacy for conserving natural ecosystems which lead to human well-being benefits such as by sustaining wild food sources and naturebased livelihoods. Negative, unintended, consequences might also emerge from the flow of new income sources into communities, as well as issues of equity.

Several issues affect the ability of the conservation sector to adequately assess contributions to human wellbeing. First, the interactions and dependencies between natural and social systems have yet to be sufficiently integrated into existing assessment frameworks, which are mainly focused on either ecological or socio-economic benefits. Second, empirical evidence demonstrating links between healthy ecosystems and human well-being is still lacking, with reporting and evaluation of conservation outcomes limited and inconsistent. Consequently, in the absence of a coherent evidence base about what works, and what does not, conservation organizations and their partners are continuing to implement interventions under assumptions about likely effects. This uncertainty brings considerable risk, as investments could fail to achieve one or both ecological and social objectives, waste scarce available resources, and damage the credibility of conservation efforts with donors, decision makers, and other stakeholders. 

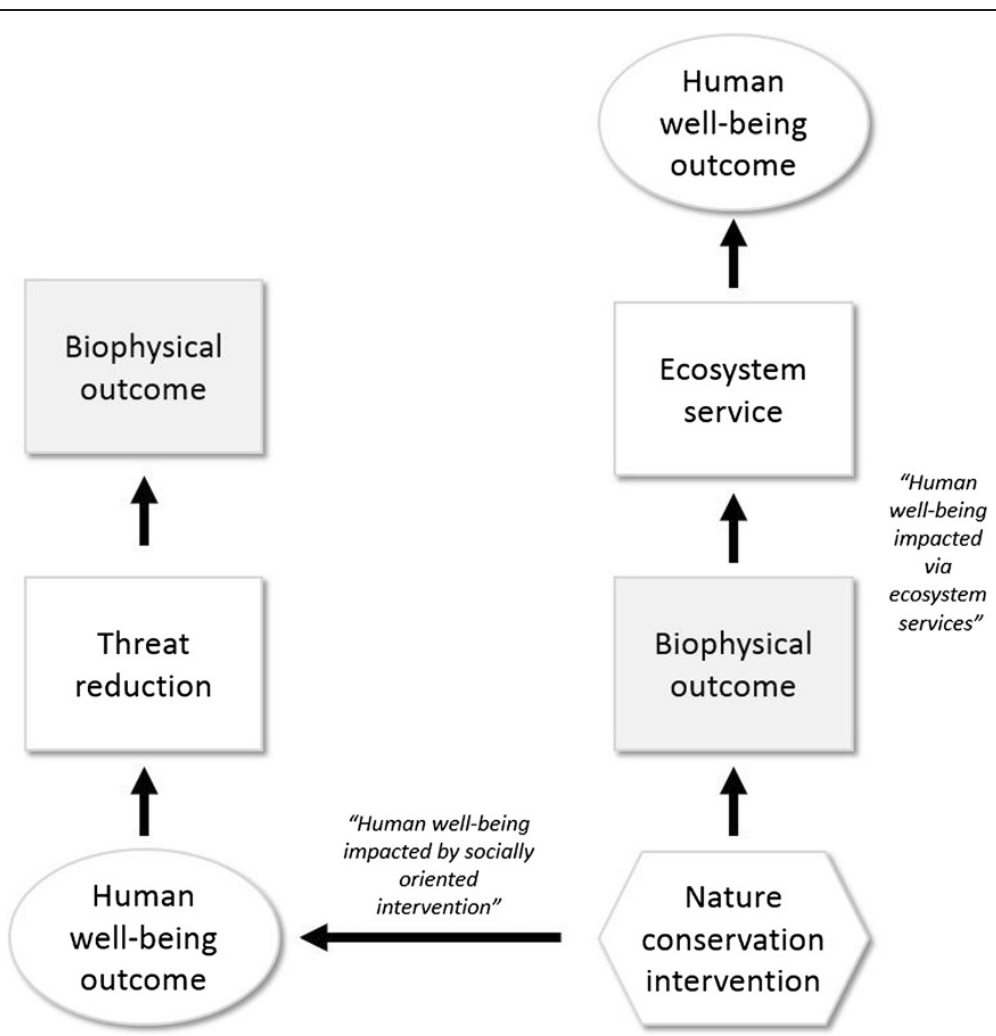

Figure 1 Conceptual model illustrating direct and indirect relationships between nature conservation interventions and human well-being outcomes.

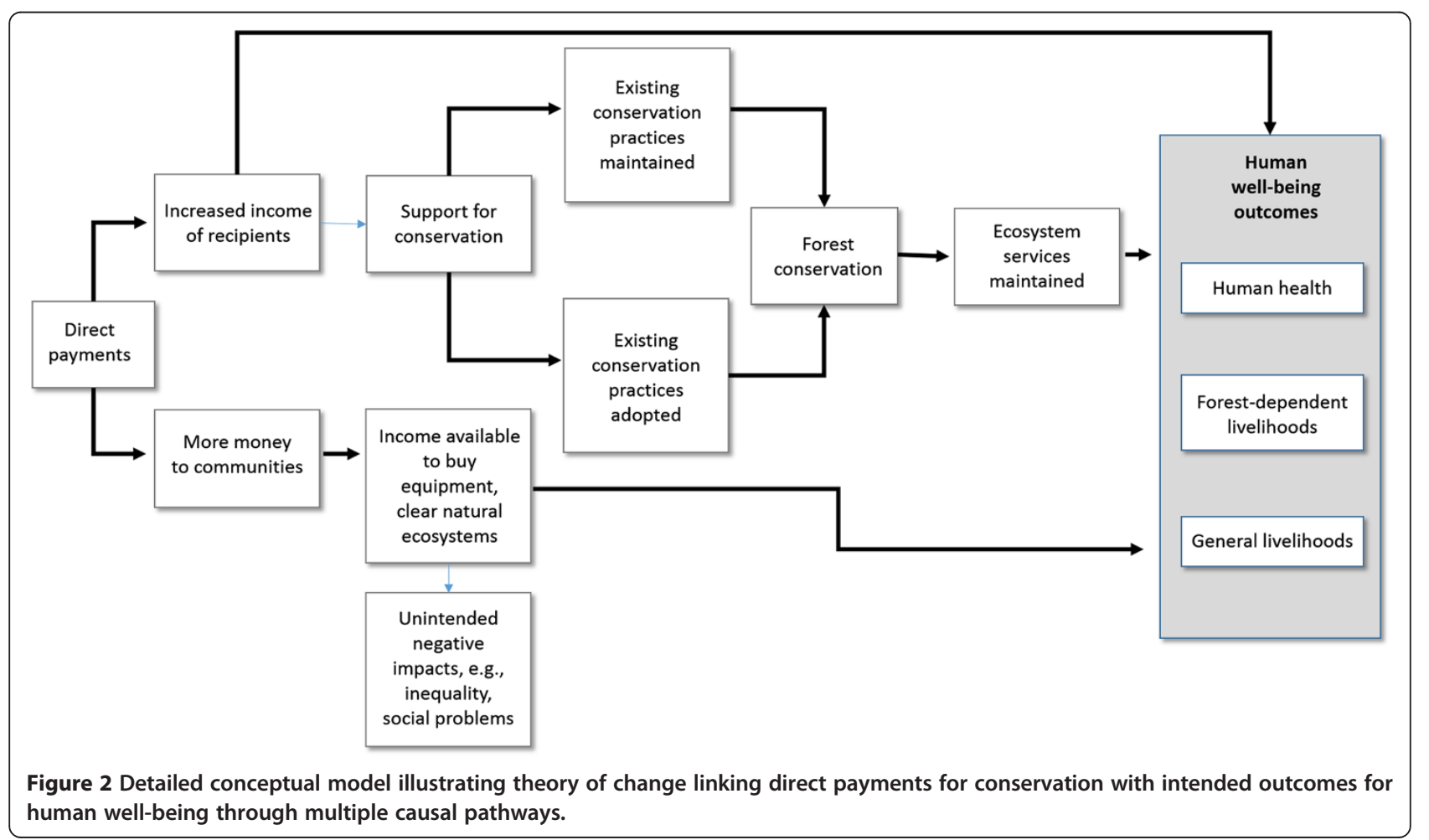


Recent studies have begun to characterize evidence on the relationships between nature and people. These efforts have related to specific types of conservation interventions (e.g., protected areas, [28]; community forest management, [29]), alternative livelihood schemes [30], payments for ecosystem services [31]; and ecocertification, [32]; and specific components of biodiversity [33]. Work has also been done to formulate frameworks for analyzing the impacts and causal pathways of specific conservation projects on both natural and social outcomes [34,35]. Recent advances are encouraging, yet existing studies have taken a more narrow focus to examining linkages between conservation and human well-being, looking at one specific type of intervention on a specific type of outcome limiting insight into interdependent contexts and outcomes $[27,36]$ and the broader landscape on which conservation outcomes play out. In contrast, our study aims to examine the impact of different types of interventions upon a wide range of possible outcomes and causal pathways. Benefits of a larger review therefore include: 1) avoiding assumptions about effects of widely applied interventions; 2) inclusion of non-traditional or lesser known interventions and dimensions of well-being; and 3) generalizability to decision making across the overall sector.

To address this question, we use systematic mapping as a tool for describing the breadth and current state of the evidence base with an aim to characterize and visually represent the causal linkages supported by this evidence base. Systematic mapping, also known as evidence gap mapping [37], is an useful method to thematically synthesize and characterize, or "map", collections of evidence, particularly to provide basis for policy decisions [38]. This technique allows identification of weak or lacking evidence on key linkages which might facilitate policy-making decisions based existing knowledge in order to direct resources most effectively. The outputs of such mapping include structured matrices depicting the distribution and frequency of studies, and coding for study design or mechanism type, across a range of interventions and outcome variables. Beyond characterizing the existing evidence base, we will apply theory of change conceptual modelling methods $[39,40]$ to define categories for organizing data (e.g., intermediate and long-term outcomes), and to interpret prevalent direct and indirect causal pathways between conservation interventions and human well-being outcomes.

\section{Aims and objectives of the systematic map}

This mapping exercise will scope and identify studies that document and/or measure the impacts of nature conservation interventions on human well-being at local to regional scales. The emphasis will be on direct effects to discrete populations, beneficiaries or targeted stakeholders, with a focus on households, communities, or individuals in developing countries, as these populations are likely to be most dependent on nature and/or most sensitive to positive or negative impacts of conservation.

The primary research question is:

What are the impacts of nature conservation interventions on different domains of human well-being in developing countries?

The systematic map will synthesize an index of literature and map the evidence illustrating the breadth of causal linkages between both positive and negative effects of nature conservation and human well-being (Table 1). The primary objective of the systematic map is to assess and characterize the current state and distribution of the existing evidence base. The map is focused on evidence related to effects of nature conservation which includes interventions primarily intended to achieve protection and management of natural ecosystems in-situ and generally excludes ex-situ interventions such as seed banks captive breeding and environmental regulatory measures, such as control of air pollution, waste management, water treatment or energy production. For our purposes, human well-being is a multi-dimensional concept, encompassing both tangible and intangible effects [41], and defined most broadly as the "the satisfaction of human needs to achieve a state of being well (i.e., healthy, happy, and prosperous), both physically and mentally" [42]. The evidence base will be explored and characterized using a targeted data extraction strategy to answer a set of secondary research questions:

- What is the current state and distribution of evidence?

- What types of impacts from conservation interventions on human well-being are measured?

- What types of ecosystem services are explicitly associated with the impacts of conservation interventions on human well-being?

- What populations are affected by conservation and/ or focus of studies?

- How does the evidence base align with major priorities and investments of implementing agencies?

This will include identifying the range of conservation interventions linked to different domains of human wellbeing, along with geographic location, duration of interventions, and the types of conservation objectives defined by studies.

Given the emphasis which contemporary conservation strategies and research place on the role of ecosystem services play in connecting conservation to human well-being, this study will also assess which services are associated with 
Table 1 Key elements of the study research question

\begin{tabular}{lll}
\hline Population & Intervention & Comparator \\
\hline $\begin{array}{l}\text { Human populations, including } \\
\text { individuals, households, communities or }\end{array}$ & $\begin{array}{l}\text { Adoption or implementation } \\
\text { of nature conservation } \\
\text { nation states in non-OECD countries }\end{array}$ & $\begin{array}{l}\text { No use of nature conservation } \\
\text { interventions either between } \\
\text { sites or groups, or over time } \\
\text { series (before/after) }\end{array}$ \\
\hline
\end{tabular}

different conservation interventions and the extent to which these studies explicitly link conservation of ecosystem services with effects on well-being.

\section{Methods}

\section{Theory of change}

Theory of change methods will be used to explore and characterize the complexity of causal linkages between conservation interventions and human well-being outcomes, particularly, with respect to the role of ecosystem services. A theory of change is a graphical illustration, generated in a participatory process, which represents how an intervention is expected to lead to planned outcomes through explicitly identifying causal links between outputs, intermediate outcomes and final outcomes along with the critical assumptions underlying those links [40]. We intend to specifically use theory of change in several ways: 1) understand the conceptual basis for the study and the types of pathways by which conservation might affect human well-being; 2) design data extraction questionnaire, and 3) present and interpret of results through framework synthesis. Progress on integration of theory of change modelling into systematic mapping design and implementation is explained below.

In an expert workshop in November 2013 (Additional file 1), hosted by Conservation International, theory of change methods were used to support development of questions for data extraction, understand prevalent pathways between conservation action and well-being outcomes,. In addition, participants articulated a high-level theory of change for the research question (see Figure 1). The role of causal mechanisms and pathways were further explored for specific interventions (example shown in Figure 2). Explicit consideration of the program theory, e.g., how the intervention is expected to lead to planned outcomes, will help the project team to identify relevant questions and test a priori hypotheses prominently used in the sector [43]. With a theory of change model, assumptions about the attribution of project strategies and activities to changes in human well-being can be articulated and rival explanations taken into consideration. We will pilot question(s) relating to identification of types of mechanisms as part of the data extraction. We are wary to attempt to articulate anticipated pathways or mechanisms by which conservation affects human wellbeing if studies do not have explicit conceptual models, e.g., theory of change models or logical frameworks.
Following full text assessment and mapping of evidence, theory of change modelling will be used to help categorize intermediate and long-term outcome variables, where possible, and code for mechanisms by which linkages between specific interventions and specific outcomes occur.

\section{Search terms}

A search string comprising the following English search terms will be used to query online bibliographic databases and internet search engines:

Intervention: ("conservation" OR "conserve" OR "conservancy" OR "protect" OR "management" OR “awareness" OR "law" OR "policy" OR "reserve" "govern" OR "capacity-build" OR "train*" OR "regulation" OR "payment for ecosystem services" OR "PES" OR "ecotourism" OR "sustainable use")

\section{AND}

Outcome: "wellbeing" OR "well-being" OR "well being" OR "ecosystem service*" OR "nutrition" OR "skill*" OR "empower" OR "clean water" OR "livelihood" OR "(food) security" OR "resilience*” OR "vulnerability" OR "(social) capital" OR "attitude" OR "perception" "(human) health" OR "human capital" OR "(traditional) knowledge")

AND

Intervention qualifiers: ("marine" OR "freshwater" OR "coastal" OR "forest" OR "ecosystem" OR "habitat" OR "biodiversity" OR "sustainab" "ecolog*" OR "integrated" OR "landscape" OR "seascape" OR "coral reef"

\section{AND}

Outcome qualifiers: ("human" OR "people" OR "person"” OR "community*" OR "household"” OR "fisher*" OR "collaborative")

The search string was developed through a scoping exercise which examined relevant frameworks and search terms from similar systematic reviews and maps [28,44] and explored the impact of alternate terms, wildcards, and use of standardized Boolean search conventions commonly used in information systems and online databases. The search string was further refined through consultation from the November 2013 expert workshop. Efficacy and relevancy of the search string was compared against a test library of $30+$ publications (Additional file 2). The test library contains publications representative of a range of intervention types and different attributes of the outcome variables of interest to this study. The test 
library will enable inadequacies in the search string to be reviewed and amended to ensure relevant studies were being captured in the search.

A record of the evolution of the search string development has been created to track modifications and additions based upon the initial scoping exercise (see Additional file 3). This will be further refined during implementation of the full search strategy. The initial string of terms was derived from existing frameworks and keywords from test library were used as inputs into the search string development process (Figure 3):

Initial searching will be conducted in English only due to resource constraints. Where studies are reported in other languages, they will be removed from the study. The total number of non-English studies will be tracked to report potential additional sources of evidence. If publications written in other languages have an English language abstract, we will screen their title and abstract for relevance and compile relevant publications into a separate database for future assessment in a follow-up phase to this initial systematic mapping exercise. This future assessment would involve generation of languagespecific search strings to capture linguistic differences in definitions of key terms associated with the research question.

Citations from online bibliographic databases will be downloaded and imported into an Endnote library for referencing and deletion of duplicates. The date of the search will be documented to enable updating by future mapping exercises.

\section{Searches}

The search will aim to capture available evidence relevant to the question, whether published or unpublished. Different sources of information, e.g., online publication databases, search engines, topical databases, and organization websites, will be searched in order to maximize the coverage of the search. Literature appearing in peerreviewed publications will be collated together with reports and documents from unpublished sources, in particular from organizations and donor agencies involved in implementation of conservation and development programs.

\section{Publication database searches}

Two peer-reviewed publication databases will be searched: SciVerse's Scopus [45] and Thomson Reuters Web of Science [46], both of which cover natural and social sciences. The search string will be modified for Scopus syntax and used to search that database's titles, abstracts, and keywords (Additional file 3). Within Web of Science, the equivalent field code is 'Topic', which also includes title, abstract and keywords. The search string will be slightly modified when applied to Web of Science because of the different way this database structures subject/ research areas. In SCOPUS, each journal is assigned one or more of the 335 'Subject Areas', each of which falls under one of 27 major subject areas, and it is these major subject areas which can be used to refine the search results (Additional file 4). Web of Science, by contrast, allocates individual articles to one or more 156 'Research Areas' which can be included or excluded in order to refine the search. While there are many overlaps between SCOPUS's subject areas and Web of Science's research areas, direct comparisons are moderately subjective. In an effort to standardize our search method, each Web of Science research area was categorized into a corresponding SCOPUS subject area (Additional file 4).

As the search string generated many hits in possibly irrelevant subject/research areas, we tested the effect of

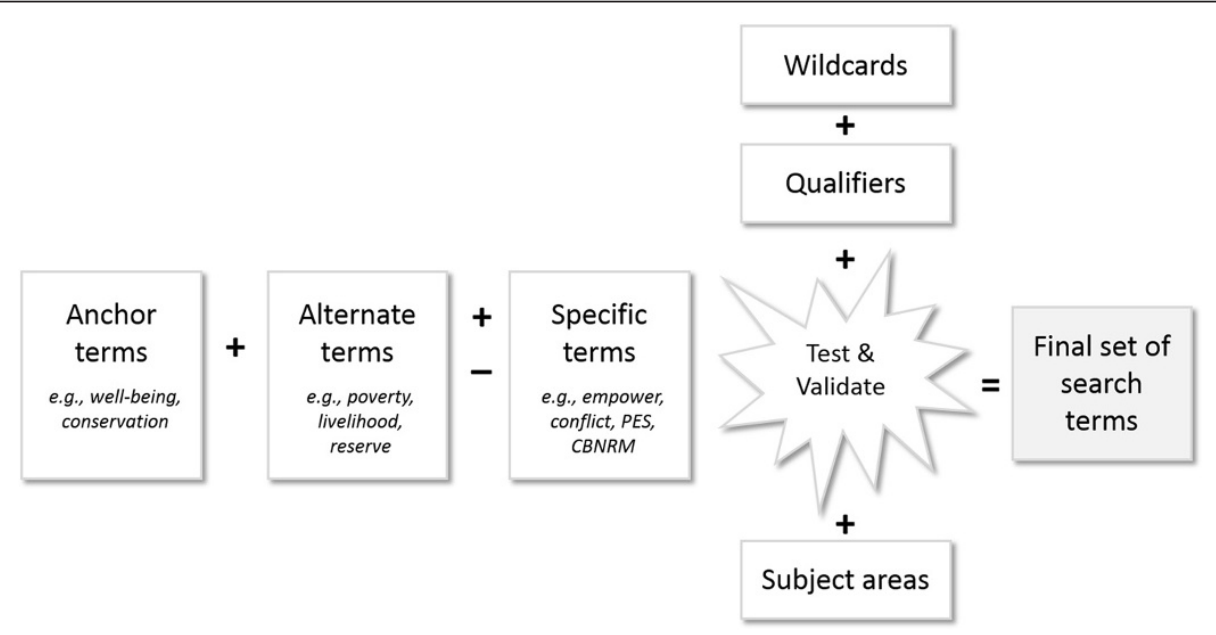

Figure 3 Scoping exercise based upon existing frameworks and reviews used to test possible search terms and derive final set for both intervention and outcome variables. 
subject area on hits using SCOPUS. We examined the effect of running 1) intervention + outcome strings, 2) intervention + outcome + nature qualifiers, and 3) the full search string, while limiting the search to one subject area at a time. This allowed us to determine which subject areas had the most hits when adding naturebased and human qualifiers - paring down search results to more relevant titles. Additional file 4 describes the subject areas that were used in the search terms scoping exercise and highlights the equivalent research areas that would need to be included or excluded in Web of Science in order to achieve a comparable result. The results from the SCOPUS search will be combined with the Web of Science results and screened for duplicates using bibliographic software Endnote.

\section{Search engine searches}

Google Scholar (scholar.google.com) will also be searched using only a select subset of terms: "conservation" OR "management" AND "well-being" OR "capital" AND "biodiversity" OR "ecosystem” AND "human" OR "community." The first 100 search results, organized by relevance, will be compared with the Web of Science and Scopus search returns to test their comprehensiveness. Articles returned by the Google Scholar search, but not found in the Web of Science and Scopus searches, will be added to the reference list.

\section{Targeted searches including grey literature}

A limited selection of 'grey' literature (i.e., published and unpublished documents that were not submitted to the peer-reviewed system collated in online databases) will be identified in a number of ways. First, the websites and portals of relevant organizations, databases and networks, as determined by experts participating in workshop, will be searched (Table 2) and relevant titles added to list of articles. Second, relevant grey literature will be identified through key informants representing constituencies likely to use results of the map. A list of key informants will aim to be as representative as possible across criteria on individual characteristics of informants (e.g., nationality, gender, and role in organization) and the organizations they are associated with (e.g., type of sector, geographic location, purpose). Using a snowballing approach, key informants will be contacted via email and asked to send relevant reports, dissertations or articles to the authors. Third, a call will made to key professional networks including the Poverty Conservation Learning Group, Conservation Measures Partnership, the Environmental Evaluators Network, Society of Conservation Biology Social Science Working Group, and the American Evaluation Association Topical Interest Group on Environment. Fourth, participants at the expert workshop held in November 2013 will be invited to review the final list of
Table 2 Websites of specialist organizations and online databases

\begin{tabular}{ll}
\hline Organization & Website \\
\hline A Rocha International & www.arocha.org \\
$\begin{array}{l}\text { AidData - open data for } \\
\text { international development }\end{array}$ & www.aiddata.org \\
Birdlife International & www.birdlife.org \\
Biodiversity Conservation Network & www.bcnet.org \\
Biodiversity Support Program & www.sustainable.org \\
CARE International & www.careinternational.org \\
Caribbean Natural Resources Institute & www.canari.org \\
Catholic Agency for Overseas & www.cafod.org
\end{tabular}

Development (CAFOD)

Centre for International Forestry

www.cifor.org

Research (CIFOR)

Conservational International (Cl)

www.conservation.org

Convention for Biological Diversity

www.cbd.int

Department for International

Development

Conservation Evidence

www.dfid.org.uk

www.conservationevidence. com

Food and Agriculture Organization (FAO)

Health and Environment Alliance

www.fao.org

www.env-health.org

International Institute for Environment and Development

The Nature Conservancy

www.iied.org

www.nature.org

International Union for the Conservation of Nature

Locally-Managed Marine Area

(LMMA) Network

Natureserve

www.iucn.org

www.Immanetwork.org

www.natureserve.org

RARE

www.rare.org

United Nations Environment

Programme (UNEP)

www.unep.org

United Nations Environment Programme - www.unep-wcmc.org World Conservation Monitoring Center (UNEP-WCMC)

United Nations Development

Programme (UNDP)

United States Agency for International

Development (USAID)

USAID Development Experience

Clearinghouse

Wildife Conservation Society

www.undp.org

World Bank

World Neighbors

www.usaid.org

dec.usaid.gov

www.wcs.org

www.worldbank.org

www.wn.org

Worldwide Fund for Nature International

www.panda.org

publications and identify any documents missing from the list. Finally, the studies identified by recent relevant evidence syntheses on effects of biodiversity on poverty 
[44] and the impact of terrestrial protected areas on human well-being [28] will also be reviewed and relevant publications included in our search.

To assist screening of grey literature for relevant publications, a text extraction ethnographic software package, Dedoose (link: www.dedoose.com) will be used to identify relevant key words and strings of search terms related to research question and inclusion criteria within the full text of documents. Full text will be reviewed for the following search terms: "human well" OR "poverty" OR "livelihood" AND "conserve*" OR "protect". This process will expedite review of grey literature, which might have more general titles or lack abstracts.

\section{Comprehensiveness of search}

The search strategy for our systematic map is largely dependent on conservation literature available on online publication databases. The two databases, Scopus and Web of Science, list articles from major conservation, environment, and development journals. The online database is limited to articles published in these journals from 1980 onwards and therefore the search will not capture articles published earlier. To expand the search for relevant evidence, a search of grey literature will be conducted. This will include websites of major organizations and key databases conducting research on social outcomes from conservation and implementing conservation interventions in developing countries. To ensure comprehensiveness of the search, alternate terms for intervention and outcome variables have been tested using a test library (Additional file 2) and disaggregated using wild cards and other variations on similar words.

Limitations to the comprehensiveness of the search include consideration of only English language publications due to time and resource constraints. Further limitations include access to grey literature and time required to collate studies from availability of studies by developing country researchers due to biases associated with peerreviewed publications and the same aforementioned language constraints.

\section{Inclusion and exclusion criteria}

Following compilation of database hits based on the search string and the removal of duplicates, the articles captured will be screened against a series of inclusion and exclusion criteria (first applied to titles and then to abstracts). Reported studies will be included in the map if they meet the following criteria:

\section{Relevant population}

- The study focuses on the well-being of individuals, households or communities, or nation states living in non-OECD countries.

\section{Relevant intervention}

- The study involves establishment, adoption, or implementation of an intervention that regulates, protects or manages biodiversity and natural ecosystems through in-situ activities.

\section{Relevant outcomes}

- The study describes effects on one or more domains of human well-being categorized as follows: Living standards (Material, Economic), Health, Education, Security/Safety, Social Wellness, Equity, Spiritual and Cultural Fulfillment, Psychological/Mental Wellbeing, Governance, and Resource Rights and Access.

\section{Relevant study designs}

- All study designs will be included if they measure the effect of a conservation intervention including impact evaluations, econometrics analyses, case studies, and observational studies. Secondary studies, e.g., systematic reviews and meta-analyses, will also be marked and set aside as a separate group.

\section{Irrelevant Population/Subject}

- Studies focusing on OECD countries will not be included;

- Studies without a discrete population such as those commenting on effects of undefined groups or populations will not be included.

\section{Irrelevant interventions}

- Studies that document, measure or observe people's daily use or interaction with natural ecosystems and/or ecosystem goods or services rather than associated with a specific and discrete external intervention will not be included;

- Studies focused on environmental regulatory measures and mitigation (air quality control, waste management, energy production) and ex-situ conservation efforts (e.g., zoos, captive breeding and seed banks).

\section{Irrelevant outcome}

- Studies that do not measure or describe human well-being outcomes or studies that only focus on biophysical outcomes of conservation.

\section{Irrelevant types of studies}

- Theoretical studies or models 
- Studies where population or subject is not defined - e.g., global public good.

- Studies that explore the effect of human well-being on biophysical conservation outcomes

\section{Screening}

Following implementation of the search strategy, all titles will be reviewed. Abstracts of articles with relevant titles from the first stage will be assessed against the inclusion and exclusion criteria above. The title and abstract review stages will be conducted by two researchers, who will scan studies based upon the criteria. If there is any doubt about the relevance of an article, it will be retained for full text assessment. The reviewers will perform a title and abstract screening of a similar random subset of reference list (up to 1000 references) in a pilot exercise to assess repeatability of the selection criteria. Articles retained following the title and abstract review stages will have a full-text assessment based upon the inclusion and exclusion criteria. The full-text assessment will take place during the process of data extraction as detailed in the following sections.

\section{Data extraction strategy}

Each article in the full-text assessment will be examined using a standard questionnaire and supplementary codebook (Additional file 5: Conservation-Human Well-Being Linkages Assessment) for categorizing the data generated from the data extraction strategy. The questionnaire was developed to capture key descriptive information about the article and framed according to the research questions relevant to this study. The questionnaire was reviewed and refined based upon feedback gathered during the November 2013 expert workshop. A form for extracting data will be developed in Google Forms, which will then automatically compile extracted data into a spreadsheet. The following broad categories of data will be extracted:

1. Bibliographic information

2. Basic information about type of conservation intervention

3. Basic information on study design and subjects

4. Human well-being outcomes

5. Outcome pathways and mechanisms affecting change

Categories for describing intervention type and outcomes have been identified a priori and compiled into a structured matrix. To develop appropriate questions to first identify mechanisms, and then characterize them, we will conduct a pilot with a subset of studies. Some potential constraints in characterizing mechanisms, include the sheer size of the systematic mapping exercise, is our hesitancy to attempt to interpret assumed relationships within a study without conceptual model or logical framework present, and potential to include all internal and external factors that might affect conservation success versus causal mechanism(s) assumed to link conservation action to changes in well-being.

\section{Study quality assessment}

Given the scope of the mapping process, we do not plan to assess the quality of included studies. By their nature, systematic maps, or evidence gap maps, are broad in scope and limited in depth in order to explore the characteristics of the evidence base rather than specific issues on quality and strength [37]. As part of the data extraction strategy, we will collate data on study design where possible and on what type of comparators are used (see further details in data extraction questionnaire in Additional file 5). Information on study design will be collected, e.g., type of data collected, sample size, duration of study, and used as a proxy to the frequency of study design types, and their relative rigor, among different studies which might indicate quality of the study design. We will however be cautious not to assert that type or frequency of study design as a substitute for confidence in the effects of specific interventions.

\section{Data mapping and presentation}

A key output of mapping existing evidence will be a structured matrix, which is a graphical illustration of the distribution and frequencies of studies to document specific relationships between a range of interventions and outcomes [37]. Evidence on different outcomes (in columns) is mapped onto different categories of interventions (in rows). Each cell represents a study. Each cell can be color-coded according to different criteria, e.g., types of study design, geographic location etc. The structured matrix will be developed using framework synthesis, which applies pre-determined categories to the data and enables structured comparison [47]. Extraction of data from individual studies will be organized based upon the structured matrix. A draft matrix is available in Additional file 6 which illustrates the range of interventions and outcomes. Using software under development by the International Impact Initiative (3ie), we intend to produce an online version of the gap map, which will enable each cell to be linked to a user-friendly summary of each study to allow the user to explore the main findings and other information on each study in more detail. Alternatively to the 3ie online system, we will also explore other knowledge management tools such as Earthcube (http://earthcube.ning.com/).

In addition to the structured matrix, all articles included in the full text assessment will be characterized using descriptive statistics on key trends, including:

\section{- Type of conservation interventions}


- Human well-being outcomes

- Type of study design

- Direction of impact

- Type of causal mechanism

Geographic locations and ecosystem types will be spatially mapped where discrete study locations are available. Given the size of the study, detailed analysis into the type and frequency of mechanisms influencing causal pathways will be limited. Where conceptual model or logical frameworks are explicit in a study, we will attempt to characterize the range of mechanisms documented and colour code studies in the structured matrix for each type of mechanism linking a specific intervention to a specific outcome.

\section{Additional files}

\section{Additional file 1: $\mathrm{Cl}$ expert workshop and list of participants. \\ Additional file 2: List of publications in test library.}

Additional file 3: Scoping of search terms and evolution of search string.xls.

Additional file 4: Comparison on Scopus subject areas and Web of Science research areas.

Additional file 5: Conservation-Human Well-being Linkages Assessment.xls.

Additional file 6: Template for structured matrix.

\section{Competing interests}

The authors declare that they have no conflicts of interest.

\section{Authors' contributions}

$M B$ jointly with $W T$ conceived the study and secured the funding support. $\mathrm{MB}$ and SC co-wrote the manuscript. JE, RG, MH, DR, SW and WT gave input on parameters of the search strategy and inclusion/exclusion criteria and provided comments on the manuscript. MB, WT, RG and SW jointly developed the data extraction strategy. MB and SC implemented scoping of the search strategy. MB will coordinate the review and the analysis and presentation of results. MB, SC, DR, and $\mathrm{MH}$ will participate in the review of full text articles. All authors read and approved the final manuscript.

\section{Acknowledgements}

The authors would like to thank all of the participants in an expert workshop in November 2013 hosted by Conservation International and Nancy Ludlow for logistical support. We also thank Andrew Pullin and Birte Snilstveit for advice on methodologies for systematic mapping, and two anonymous reviewers whose comments improved this manuscript. We are grateful for funding support from the Gordon and Betty Moore Foundation (Grant No. 3519).

\footnotetext{
Author details

${ }^{1}$ Conservation International, 2011 Crystal Drive, Suite 500, Arlington, VA 22202, USA. ²Department of Ecology and Evolutionary Biology, University of California, Los Angeles, Los Angeles, CA, USA. ${ }^{3}$ University of Exeter, European Centre for Environment \& Human Health, Truro, United Kingdom. ${ }^{4}$ The Nature Conservancy, Worldwide Office, Arlington, VA, USA. ${ }^{5}$ International Institute for Environment and Development, 80-86 Grays Inn Road, London WC1X 8NH, UK. ${ }^{6}$ Department of Geography \& Environmental Systems, University of Maryland-Baltimore County, 1000 Hilltop Cir, Baltimore, MD 21250, USA.
}

Received: 26 February 2014 Accepted: 7 June 2014

Published: 5 August 2014

\section{References}

1. IUCN, UNEP and WWF: World Conservation Strategy. Gland, Switzerland: International Union for Conservation of Nature with the United Nations Environment Programme and the Worldwide Wildlife Fund for Nature; 1980.

2. Robinson J: The Limits to Caring: sustainable living and the loss of biodiversity. Conserv Biol 1993, 7:20-28.

3. Holdgate M: The Green Web: A Union for World Conservation. London: Earthscan; 1999.

4. MEA: Ecosystems and human well-being: Policy Responses: Findings of the Responses Working Group of the Millennium Ecosystem Assessment. In Washington, D.C: Island Press; 2005.

5. TEEB: The Economics of Ecosystems and Biodiversity: Mainstreaming the Economics of Nature: A synthesis of the approach, conclusions and recommendations of TEEB. 2010

6. Secretariat for the Convention on Biological Diversity: Convention on Biological Diversity. 1992.

7. UN: Report of the United Nations Conference on Sustainable Development. In New York, NY: United Nations; 2012.

8. UN: The Millennium Development Goals Report. In New York, NY: United Nations; 2013.

9. Leisher C, Sanjayan M, Blockhus J, Larsen N, Kontoleon A: Does conserving biodiversity work to reduce poverty? A state of knowledge review. In Does conserving biodiversity work to reduce poverty? A state of knowledge review). pp. 143-159. Arlington, VA: The Nature Conservancy, University of Cambridge, IIED; 2012:143-159.

10. Roe D: Walpole MJ (Eds.): Whose Value Counts? Trade-offs between Biodiversity Conservation and Poverty Reduction. Wiley-Blackwell in association with the Zoological Society of London: Chichester; 2010.

11. CCBA: Climate, Community \& Biodiversity Standards. Third Edition. In Arlington, VA: CCBA; 2013.

12. CMP: Open standards for the practice of conservation. Version 3.0. In Washington, D.C: Conservation Measures Partnership; 2013.

13. Stephanson SL, Mascia MB: Putting people on the map: An approach to integrating social data in conservation planning. In Washington, D.C Society of Conservation Biology SSWG Working Paper 1; 2009.

14. Turner WR, Brandon K, Brooks TM, Gascon C, Gibbs HK, Lawrence KS, Mittermeier RA, Selig ER: Global biodiversity conservation and the alleviation of poverty. Bioscience 2012,62.

15. Stocking $M$, Perkin S: Conservation-with-development: an application of the concept in the Usambara Mountains, Tanzania. T I Brit Geogr 1992, 17:337-349.

16. Kremen C, Lance K, Raymond I: Interdisciplinary tools for monitoring conservation impacts in Madagascar. Conserv Biol 1998, 12:549-563.

17. Baral N, Stern M, Heinen J: Integrated Conservation and Development Project Life Cycles in the Annapurna Conservation Area, Nepal: Is Development Overpowering Conservation? Biodiversity Conserv 2007, 16:2903-2917.

18. Salafsky N, Wollenberg V: Linking livelihoods and conservation: a conceptual framework and scale for assessing the integration of human needs and biodiversity. World Dev 2000, 28:1421-1438.

19. Gleason M, McCreary S, Miller-Henson M, Ugoretz J, Fox E, Merrifield M, McClintock W, Serpa P, Hoffman K: Science-based and stakeholder-driven marine protected area network planning: A successful case study from north central California. Ocean Coast Manage 2010, 53:52-68.

20. Woodroffe R, Thirgood SJ, Rabinowitz A: People and Wildlife: Conflict Or Coexistence? In Cambridge, UK: Cambridge University Press; 2005.

21. Brockington D, Igoe J: Eviction for conservation: a global overview. Conserv Soc 2006, 4:424-470.

22. USAID: USAID Biodiversity Policy. Washington, D.C: United States Agency for International Development; 2014.

23. Yang W, Dietz T, Liu W, Luo J, Liu J: Going beyond the Millennium Ecosystem Assessment: An index system of human dependence on ecosystem services. PLoS One 2013, 8:e64581.

24. Barrett CB, Brandon K, Gibson C, Gjertsen H: Conserving tropical biodiversity amid weak institutions. Bioscience 2001, 51:497-502.

25. Barrett CB, Gibson CC, Hoffman B, McCubbins MD: The complex links between governance and biodiversity. Conserv Biol 2006, 20:1358-1366.

26. Smith LM, Case JL, Smith HM, Harwell LC, Summers JK: Relating ecosystem services to domains of human well-being: Foundations for a US index. Ecol Indic 2012, 28:79-90

27. Agrawal A, Redford K: Poverty, development, and biodiversity conservation: Shooting in the dark?. Wildlife Conservation Society: Bronx, NY; 2006. 
28. Ferraro PJ, Hanauer MM: Quantifying causal mechanisms to determine how protected areas affect poverty through changes in ecosystem services and infrastructure. Proc Natl Acad Sci 2014, 111.

29. Pullin AS, Bangpan M, Dalrymple S, Dickson K, Haddaway HR, Healey JR, Hauari $\mathrm{H}$, Hockley $\mathrm{H}$, Jones JPG, Knight T: Human well-being impacts of terrestrial protected areas. Environ Evid 2013, 2:19.

30. Bowler DE, Buyung-Ali LM, Healey JR, Jones JPG, Knight TM, Pullin AS: Does community forest management provide global environmental benefits and improve local welfare. Front Ecol Evol 2012, 10:29-36.

31. Alternative Livelihoods Projects and Conservation: A systematic review for evidence based policy. [http://www.cifor.org/fileadmin/subsites/ebf/ pubs/Call_for_key_references.pdf]

32. Wunder S: The efficiency of payments for environmental services in tropical conservation. Conservation Biology 2007, 21:48-58.

33. Blackman A, Rivera J: The evidence base for environmental and socioeconomic impacts of "sustainable" certification. In Washington, D.C: Environment for Development, Resources for the Future; 2010.

34. Roe D, Sandbrook C, Fancourt M, Schulte B, Munroe R, Sibanda M: A systematic map protocol: which components or attributes of biodiversity affect which dimensions of poverty? Environmental Evidence 2013, 2:8.

35. Tallis H, Kareiva P, Marvier M, Chang A: An ecosystem services framework to support both practical conservation and economic development. Proceedings of the National Academy of Sciences 2008, 105:9457-9464.

36. Persha L, Agrawal A, Chhatre A: Social and ecological synergy: local rulemaking, forest livelihoods, and biodiversity conservation. Science 2011, 331:1606-1608.

37. Gurney GG, Cinner J, Ban N, Pressey R, Pollnac R, Campbell S, Tasidjawa S, Setiawan F: Poverty and protected areas: An evaluation of a marine integrated conservation and development project in Indonesia. Global Environmental Change 2014, 26:98-107.

38. Snilstveit B, Vojtkova M, Bhavsar A, Gaarder M: Evidence gap maps: a tool for promoting evidence-informed policy and prioritizing future research. In Washington, D.C: World Bank Policy Research Working Paper No. 6725; 2013.

39. Bates S, Clapton J, Coren E: Systematic Maps to support the evidence base in social care. Evidence \& Policy 2007, 3:539-551.

40. White H: Theory-based Impact Evaluation: Principles and Practice. Working Paper 3. International Initiative for Impact Evaluation: Washington, D.C; 2009.

41. Funnell SC, Rogers PJ: Purposeful program theory: Effective use of theories of change and logic models. Wiley; 2011.

42. Russell R, Guerry AD, Balvanera P, Gould RK, Basurto X, Chan KMA, Klain S, Levine J, Tam J: Humans and nature: How knowing and experiencing nature affect well-being. Annual Reviews of Environment and Resources 2013, 38:473-502.

43. Snilstveit B: Systematic reviews: from 'bare bones' reviews to policy relevance. Journal of Development Effectiveness 2012, 4:388-408.

44. Roe D, Fancourt M, Sandbrook C, Sibanda M, Giuliani A, Gordon-Maclean A: Which components or attributes of biodiversity influence which dimensions of poverty? Environmental Evidence 2014, 3:3.

45. Scopus. Available from: [http://www.scopus.com/]

46. Thomson Reuters: Web of Science. Available from [www.wokinfo.com/ WebOfScience]

47. Dixon-Woods M: Using framework-based synthesis for conducting reviews of qualitative studies. BMC Medicine 2011, 9:39.

doi:10.1186/2047-2382-3-16

Cite this article as: Bottrill et al:: What are the impacts of nature conservation interventions on human well-being: a systematic map protocol. Environmental Evidence 2014 3:16.

\section{Submit your next manuscript to BioMed Central and take full advantage of:}

- Convenient online submission

- Thorough peer review

- No space constraints or color figure charges

- Immediate publication on acceptance

- Inclusion in PubMed, CAS, Scopus and Google Scholar

- Research which is freely available for redistribution

Submit your manuscript at www.biomedcentral.com/submit
Ciomed Central 